\title{
La eficacia de la normativa sobre transparencia: percepciones de los responsables municipales en España
}

\section{The effectiveness of transparency regulations: perceptions of municipal officials in Spain}

\section{NOTA BIOGRÁFICA}

Raquel Valle Escolano

Universidad Carlos III de Madrid (España)

ORCID: http://orcid.org/0000-0003-4100-3905

valle.escolano@gmail.com

Raquel Valle Escolano es Licenciada y Doctora en Derecho, así como Licenciada en Ciencias Políticas y de la Administración. Es profesora de Derecho y Ciencias Políticas de las Universidades Carlos III, Universitat Oberta de Catalunya (UOC), y Universidad Internacional de Valencia (VIU). Sus líneas de investigación son la Transparencia, así como los Derechos de las personas con discapacidad.

\section{RESUMEN}

Las leyes de transparencia estatal y en muchos casos autonómicas, llevan poco tiempo implantadas en la Administración local española, lo que no impide evaluar su impacto hasta la fecha en toda una serie de terrenos clave, como son la eficacia y eficiencia de la Administración, la lucha contra la corrupción, la promoción de la participación ciudadana, la rendición de cuentas, o la mejora de la organización de la información municipal, entre otros ámbitos. Este es el objetivo de este trabajo, que utiliza como técnicas de investigación una encuesta a una importante muestra de municipios españoles (339), de tamaños diversos y encuadrados en todas las CC.AA, así como entrevistas semi-estructuradas en profundidad a responsables políticos y técnicos de la transparencia. El estudio constata valoraciones relativamente modestas de los efectos de la normativa de transparencia en relación a todas las consecuencias analizadas, que son todavía menores con respecto a algunos de sus efectos más buscados, como la lucha contra la corrupción, o la promoción de una mayor participación ciudadana, salvo en los ayuntamientos de mayor tamaño, donde el grado de cumplimiento de la ley por parte de la administración y el interés de la ciudadanía por la información son mayores.

\section{PALABRAS CLAVE}

Transparencia; Administración local; Gobierno abierto municipal; Efectos de las normativas de transparencia.

\begin{abstract}
State and in many cases regional transparency laws have only been implemented for a short time in the Spanish local administration, which does not prevent from assessing their impact until today on a range of key areas, such as the effectiveness and efficiency of the administration, the fight against corruption, the promotion of citizen participation, accountability, or the improvement of the organization of municipal information, among other fields. This is the objective of this work, which uses as research techniques a survey of a large sample of Spanish municipalities (339), of different sizes and framed in all the Autonomous Communities, as well as in-depth semi-structured interviews with political and technical responsibles of transparency in municipalities. The study finds relatively modest assessments of the effects of the transparency regulation in relation to all the consequences analyzed, which are even lower with respect to some of its most sought after effects, such as fighting against corruption, or promoting greater
\end{abstract}


GAPP. Nueva Época - N. 27, noviembre 2021 - ISSN: 1989-8991 - DOI: https://doi.org/10.24965/gapp.i27.10872 - [Págs. 30-48]

La eficacia de la normativa sobre transparencia: percepciones de los responsables municipales en España

Raquel Valle Escolano

citizen participation, except in larger municipalities, where the degree of compliance with the law by the administration and the interest of citizens for public information are greater.

\section{KEYWORDS}

Transparency; Local Public Administration; municipal open government; Effects of transparency regulations.

\section{SUMARIO}

1. INTRODUCCIÓN. 2. MARCO TEÓRICO DE LA TRANSPARENCIA. 3. METODOLOGÍA. 3.1. ANÁLISIS Y ESTUDIO DE FUENTES DOCUMENTALES. 3.2. ENCUESTA A UNA AMPLIA MUESTRA DE LOS AYUNTAMIENTOS ESPAÑOLES. 3.3. REALIZACIÓN DE ENTREVISTAS EN PROFUNDIDAD ESPECIALIZADAS. 4. RESULTADOS Y DISCUSIÓN. 4.1. LA EFICACIA DE LAS LEYES DE TRANSPARENCIA EN LOS MUNICIPIOS. 4.2. VALORACIÓN DE LOS DIVERSOS EFECTOS DE LA TRANSPARENCIA. 5. CONCLUSIONES. REFERENCIAS BIBLIOGRÁFICAS Y LEGISLATIVAS.

\section{INTRODUCCIÓN ${ }^{1}$}

La transparencia de las entidades públicas está íntimamente vinculada, en sentido positivo, con todos los valores que la buena gobernanza quiere promover, y de ahí que su implantación en las sociedades contemporáneas, más allá de abrir ventanas y mostrar la gestión de los asuntos públicos a la ciudadanía, persiga la búsqueda de toda una serie de efectos que deberían andar parejos a la misma, entre los cuales ocupan una posición destacada la rendición de cuentas, la participación ciudadana, mayores grados de eficacia y eficiencia de la administración, así como la prevención de la corrupción y la consecución de una democracia de calidad.

Precisamente en esta línea de investigación se inserta el presente trabajo, que forma parte de una investigación más amplia, que pone directamente el foco en la administración local española, buscando tomar la temperatura al nivel de transparencia alcanzado en los ayuntamientos. En particular, en estas páginas se documenta el análisis de las experiencias de los municipios, desde el momento de entrada en vigor de la ley estatal y de las leyes autonómicas, a través del estudio de las percepciones acerca del grado de efectividad de la normativa de transparencia, y su objetivo central es medir en qué medida los protagonistas de dicho proceso, responsables políticos y empleados públicos, estiman que se han conseguido las consecuencias más buscadas por dicha regulación en las distintas áreas en las que dichas leyes buscaban incidir: mejora de la gestión, avances en la organización y flujo de la información municipal, ejercicio de los derechos ciudadanos, prevención de la corrupción o satisfacción de la población, entre otras cuestiones.

Las expectativas de las normativas de transparencia son, en este sentido, muy elevadas, y el tiempo transcurrido desde su implantación nos permite ya llevar a cabo estudios sobre la efectividad de las mismas, que midan dicho factor a través, en este caso, de las percepciones de los protagonistas de su implantación. Esta era la pregunta clave de la investigación, si se habían conseguido, y en qué grado, los efectos que la transparencia persigue, y éste es precisamente uno de los factores principales que centra el interés de este trabajo, dado que no existen investigaciones sobre la materia en la Administración local: el evaluar los eventuales logros de las normativas, especialmente en una materia novedosa y revolucionaria, como lo fue la implantación de la transparencia en España. Su temática lo convierte en un estudio sugerente, que puede servir de base para otros, del mismo modo que lo hace su riqueza metodológica, dado que se apoya en fuentes documentales, al tiempo que combina técnicas de investigación de índole cuantitativa -encuesta a una importante muestra de municipios españoles (339), de tamaños diversos y encuadrados en todas las CC.AA- y cualitativa -entrevistas semi-estructuradas en profundidad a responsables políticos y técnicos de la transparencia municipal-.

El trabajo hace un recorrido a través numerosos e interesantes estudios de transparencia, fundamentalmente centrados en el ámbito local; presenta en detalle su metodología, y argumenta sus hallazgos más importantes en las diversas cuestiones analizadas. La investigación confirma una la existencia de valoraciones relativamente modestas de la implantación de la normativa de transparencia en relación a prácticamente todos los efectos que la misma persigue, que son aún menos relevantes, incluso, con relación a algunos de sus objetivos más buscados.

1 La redacción inicial de este artículo sin duda se ha beneficiado de las interesantes sugerencias realizadas por las personas que han llevado a cabo su evaluación, corrección y edición, cuya labor aprovecho para agradecer. 


\section{MARCO TEÓRICO DE LA TRANSPARENCIA}

Son numerosos los estudios que han abordado la conexión entre la transparencia y toda una serie de importantes factores, ya citados, que su implantación busca conseguir. En primer lugar, resulta indiscutible la estrecha relación entre transparencia y rendición de cuentas, ya que la primera constituye el paso inicial para que pueda darse la segunda. En la literatura académica, son diversas las interpretaciones en torno al vínculo entre la transparencia y la responsabilidad. Así, tiene un importante peso en el discurso contemporáneo la opinión de que un mayor nivel de transparencia genera más responsabilidad (Armstrong, 2005; Fox, 2007), aunque lo cierto es que tal afirmación no se ha demostrado empíricamente, dada la evidente dificultad de probarla sin considerar al tiempo otros factores. Sí encontramos importante consenso, sin embargo, en la naturaleza del vínculo entre los dos conceptos, ya que una importante mayoría de autores abordan la transparencia como una dimensión de la responsabilidad (por todos, Bovens, 2007); en sentido inverso se pronuncia Gray (1992), entendiendo que el desarrollo de la rendición de cuentas aumenta la transparencia de las organizaciones. Mulgan (2012) señala que la revelación de información es el primer paso hacia un gobierno representativo responsable, del mismo modo que lo son las prácticas de gobierno abierto y las leyes de Libertad de Información. A esta línea interpretativa se adscribe Bovens (2007), para quien la transparencia parece ser una condición necesaria pero insuficiente para la rendición de cuentas. Meijer (2014), así como Michels y Meijer (2008), proponen varias direcciones de la relación entre ambos conceptos, destacando que la transparencia puede facilitar la responsabilidad horizontal siguiendo una ruta directa, esto es, mediante la rendición de cuentas de la administración hacia los ciudadanos, o bien empleando una vía indirecta, en la que la transparencia actúa fortaleciendo la responsabilidad vertical: a través de su acceso a los datos, los ciudadanos pueden conocer las prácticas administrativas y denunciar las disfunciones ante las autoridades competentes. En definitiva, vemos que transparencia y rendición de cuentas o accountability observan una estrecha relación, concibiéndose la transparencia en términos generales como un requisito para que pueda darse la rendición de cuentas. Si no existe información, como señala Andreas Schedler (2011), no podrá haber accountability.

De igual modo se han subrayado los vínculos entre transparencia y eficiencia, desde prismas bien diversos. Uno de ellos es el que expresa Cunill (2006), al presentar la transparencia como incentivo para aumentar la eficiencia, a través de varias líneas de acción: en primer lugar, actúa reduciendo las asimetrías de información en los procesos de elaboración de normas y/o de formulación de políticas, previniendo monopolios al facilitar la competencia entre ideas, argumentos y políticas (Florini, 2000; Cunill, 2006); la competencia generada por la difusión de resultados en el proceso de evaluación de la gestión pública, favorece asimismo mayores grados de eficiencia de las entidades públicas; finalmente, en ciertas organizaciones cuya labor depende de la colaboración voluntaria de la ciudadanía, esta cooperará en mucha mayor medida si percibe que el funcionamiento de la institución es transparente para el público, ya que este elemento genera confianza. Todas las anteriores son situaciones en las que la transparencia puede ser un motor de la eficiencia por vía indirecta. Por supuesto que todas estas creencias, con ser predominantes, no impiden que algunos estudios muestren resultados contradictorios, como el realizado a nivel local por Grimmelikhuijsen (2012), que constató que un mayor grado de transparencia en relación con la documentación soporte de la toma de decisiones generaba una disminución de las percepciones en torno a la competencia de las autoridades municipales.

Por su parte, Villoria (2012) también pone de relieve cómo la transparencia, vinculada al uso de las nuevas tecnologías, produce incrementos de eficiencia notables. Lo hace a través de diversas herramientas que sirven al open government, a través de las cuales se consigue agregar datos y generar conocimiento, ya que el feedback de los usuarios de muchas plataformas y bases de datos permite al sistema su mejora continua.

Finalmente, son diversos los autores (por todos, Stiglitz, 2000, 2002) que han resaltado los efectos beneficiosos que la transparencia tiene sobre la economía de los países, sentando evidencias que permiten concluir qué la misma correlaciona muy fuertemente con los ingresos per cápita (Villoria, 2018). Los países más transparentes poseen mejores indicadores económicos, que posibilitan un mejor funcionamiento de los mercados, aportando información fiable a productores, inversores y consumidores (Islam, 2003). Con ideas parcialmente coincidentes y apoyándose en argumentos muy similares, Villoria (2018), siguiendo esquemas explicativos ya apuntados por Bellver y Kauffman (2005), subraya las aportaciones de la transparencia a la buena gobernanza y con ella a la eficacia gubernamental, al reducir las incertidumbres del mercado sobre las preferencias de los policy makers, creando mercados financieros más eficientes y políticas monetarias más predecibles, generando con ello confianza entre los stakeholders de las diversas organizaciones e incentivando las inversiones; en definitiva, a través de su efecto en la prevención y en el control de la corrup- 
ción, la transparencia mejora la eficiencia de la economía y su atracción de inversiones, contribuyendo a la calidad regulatoria y al crecimiento económico de países y mercados.

Finalmente, la utilidad de la transparencia en relación con la prevención de la corrupción y la consecución de una democracia de calidad, ha merecido una prolija e importante atención en la literatura académica. Las ideas clave subrayan que la corrupción constituye uno de los problemas más importantes que existen en el mundo actual; no solo socava la confianza de los ciudadanos en el sistema democrático, sino que actúa como variable fundamental en el desarrollo económico (Jiménez González, 2013; Villoria et al., 2016), ya que mina la credibilidad social y económica de los países (Lizcano, 2008). La existencia de altos niveles de corrupción limita la inversión y el desarrollo y provoca la ineficacia de los gobiernos (Rose-Ackerman, 2001). Se trata, pues, de un fenómeno con claros efectos perversos, que deslegitima la acción pública, incentiva la apatía ciudadana y la desafección política (Chong et al., 2011, Solé Ollé y Sorribas Navarro, 2014), genera inequidad y destruye la confianza en instituciones y gobiernos (Prats, 2007), factor este último que constituye la base misma de la democracia,

En este contexto, la transparencia se presenta como un mecanismo útil de lucha contra la corrupción, que actúa a través de su prevención. Ponce Solé (2012) señala que la transparencia funciona como un presupuesto necesario de la objetividad y la eficacia, generando con ello una buena administración. Y los diseños organizativos y procedimentales que promueven la transparencia y la buena administración, constituyen mecanismos preventivos de la actuación pública negligente o dolosa que se encuentra en la base de la corrupción (Cunill, 2006). Cierto que algunos planteamientos critican la teoría del principal agente en que se fundan los efectos beneficiosos de la apertura de información, señalando que la disminución de la corrupción puede no depender, al menos únicamente, del nivel de transparencia alcanzado (Bauhr y Grimes, 2012). Con todo, se trata de meros matices que no empañan la creencia general de que un mayor grado de transparencia ayudaría a detectar mejor los casos de corrupción existentes y, con ello, desincentivaría las actividades corruptas. Y no solo eso; y es que la transparencia se ofrece también como un arma para combatir la desafección ciudadana.

Finalmente, uno de los efectos más valiosos de la transparencia es su potencial contribución a la calidad democrática, ya que todos los criterios que marcan el camino a una democracia de calidad, y que según Dahl (1999), citado por Villoria (2012), serían la participación, elecciones libres, una adecuada comprensión de políticas y alternativas, control del gobierno y derechos de la ciudadanía, exigen instituciones adecuadas, que no podrían funcionar sin transparencia. Por otro lado, la crisis del modelo actual de democracia liberal representativa, requiere una relegitimación, que pasa por la implantación de una nueva gobernanza pública (Villoria et al., 2016), uno de cuyos pilares lo constituye la administración abierta y transparente. En la misma línea, Villoria y Cruz (2015), Constant (1988) y Bentham (1962), subrayan la fundamental importancia de la transparencia para generar confianza entre los gobernados y el gobierno, para procurar la justicia y la legitimidad democrática. Y es que la democracia requiere ciudadanos informados, que puedan juzgar la actividad del gobierno y, con base en la información, participar y tomar mejores decisiones; de ahí que una de las estrategias de reforma más necesarias y profundas que demanda nuestra democracia, se articula en torno al valor de la transparencia (Villoria, 2012). Ello sin perjuicio de la existencia de estudios que, realizados en el ámbito internacional (EE.UU), han constatado la existencia de una relación ligeramente negativa entre la mera conciencia de los derechos y requisitos de transparencia (la denominada transparencia latente) y la confianza en las agencias gubernamentales (Grimmelikhuijsen, Piotrowski y Van Ryzin, 2020).

No es, pues, de extrañar que todos los posibles efectos de la transparencia apuntados en la literatura académica, fueran directamente aludidos en los preámbulos de las leyes de transparencia vigentes en la Administración local española, tanto la estatal (Ley 19/2013, de 9 de diciembre, de Transparencia, Acceso a la Información Pública y Buen Gobierno, LTAIPBG), como gran número de leyes autonómicas en la materia².

Así, comenzando por la normativa estatal básica, ya en el debate parlamentario se repetía y subrayaba hasta la saciedad, prácticamente en cada una de las sesiones, que este texto legal era una herramienta

2 La mayoría de leyes autonómicas de transparencia resultan asimismo aplicables a las entidades locales de su ámbito territorial y a su sector público, aunque un reducido grupo de las mismas no lo son. Entre las primeras, por citar algunas, encontramos la Ley 1/2014, de 24 de junio, de Transparencia Pública de Andalucía; la Ley de Transparencia de la Actividad Pública y Participación Ciudadana de Aragón, Ley 8/2015, de 25 marzo; la Ley del Principado de Asturias 8/2018, de 14 de septiembre, de Transparencia, Buen Gobierno y Grupos de Interés; o la Ley catalana 19/2014, de 29 de diciembre, de Transparencia, Acceso a la Información Pública y Buen Gobierno. En el segundo grupo se sitúan, entre otras, la Ley gallega 1/2016, de 18 de enero, de Transparencia y Buen Gobierno; o la Ley 12/2014, de 16 de diciembre, de Transparencia y Participación Ciudadana de la Comunidad Autónoma de la Región de Murcia. 
clave para salvar la desafección de la ciudadanía con la clase política y salvar una democracia representativa profundamente herida. Tanto desde las distintas sensibilidades políticas, como por parte de numerosos expertos, se menciona que la ley es parcialmente producto de los casos de corrupción, lo cual es bueno y es malo ${ }^{3}$, señalando que la misma está llamada a resolver los problemas que gravitan sobre la coyuntura política del momento en que nació la ley. También se sitúa esta norma en el contexto de corrupción vivido en nuestro país, producto de la «borrachera económica y de un nivel de exigencia ética muy bajo por parte de la ciudadanía» ${ }^{4}$; se lamenta que la ley, en algunos aspectos y desde el punto de vista mediático, haya pasado de ser, más que una ley de transparencia, una ley anticorrupción, cosa que les parece negativa ${ }^{5}$; o se critica abiertamente el concepto «defensivo» de la ley ${ }^{6}$, que se ha erigido en una especie de «vacuna contra la corrupción ${ }^{7}$. Se apunta que la transparencia es una exigencia clara de la sociedad civil 8 ; que la misma despierta unas "expectativas atribuibles al contexto que no son justas» ${ }^{9}$, y que exceden las que se esperarían de una ley de transparencia más convencional; criticando que la norma pretenda solucionar objetivos que no corresponden strictu sensu a su razón de ser:

«Es una ley que empezó siendo una ley de transparencia, pero que ha terminado siendo un vehículo legislativo en el que se quiere dar satisfacción a la demanda ciudadana de petición de cuentas a la clase política, se quiere resolver el problema de la corrupción en España, se quiere resolver el encaje y la regulación de la Casa Real y de los partidos políticos» ${ }^{10}$.

En definitiva, más allá de regular la transparencia, se trata de una ley contra la desafección y a favor del fortalecimiento de la democracia representativa, situándola como una de las «iniciativas de reforma institucional que la sociedad demanda y la democracia precisa para mantener el vigor y la fortaleza con que naciós ${ }^{11}$. Se busca recuperar la credibilidad perdida ${ }^{12}$, se persigue que la ley contribuya a restaurar puentes rotos entre los representantes políticos con la ciudadanía, una idea que está meridianamente clara en la intervención del diputado Olabarría Muñoz:

"Quiero indicarle que nos estamos jugando mucho con leyes de esta naturaleza; nos estamos jugando.... una cierta recuperación de la sintonía que otrora existió con los ciudadanos y que en este momento se ha perdido, ha sufrido una ruptura abrupta. (...) Aquí estamos hablando de transparencia; la gente habla de transparencia, los representantes que estamos en esta Comisión hablamos de transparencia, pero no deja de ser un lapsus linguae, estamos hablando de otra cosa: estamos intentando recuperar nuestra conexión vital con los ciudadanos a los que representamos, ciudadanos que en su abrumadora mayoría, de forma abrumadoramente mayoritaria ya no nos consideran sus representantes» ${ }^{13}$.

Una opinión compartida con expertos que participaron de lleno en el proceso de aprobación de la ley. Por todos, Guichot (2014), quien subraya la situación de profundísima crisis institucional y de confianza en la política, absolutamente presente en el debate parlamentario, como demuestra el número de veces que en el mismo se repitieron los términos «regeneración democrática» y «corrupción».

Junto a estos importantes efectos, fruto en gran medida del momento político que vivía nuestro país cuando vio la luz esta ley, la norma menciona otros no menos relevantes, en gran parte relacionados, cuando destaca que los países con mayores niveles en materia de transparencia y normas de buen gobierno cuentan con instituciones más fuertes, que favorecen el crecimiento económico y el desarrollo social. Y continúa

3 Así lo señaló Emilio Olabarría, del Grupo Parlamentario Vasco. DSCD n. ${ }^{\circ}$ 248, de 23 de enero de 2013 , p. 20.

4 Garrigues Walker, representante del Comité Ejecutivo de Transparencia Internacional España. DSCD n. 248, de 23 de enero de 2013, p. 27.

5 Afirmación realizada, por el Grupo Parlamentario Socialista, por la diputada Batet Lamaña. DSCD n. ${ }^{\circ} 254$, de 12 de febrero de 2013, p. 11.

6 En opinión del señor Nuet Pujals, por el Grupo de La Izquierda Plural. DSCD n. ${ }^{\circ} 254$, de 12 de febrero de 2013 , p. 30.

7 Son palabras de Emilio Olabarría, del Grupo Parlamentario Vasco. DSCD n. ${ }^{\circ}$ 290, de 20 de marzo de 2013 , p. 17.

8 Martínez Gorriarán, por el Grupo Parlamentario de Unión Progreso y Democracia. DSCD n. ${ }^{\circ} 290$, de 20 de marzo de 2013 , p. 19.

9 De la Nuez Sánchez-Cascado, abogada del Estado en excedencia, miembro de la Coalición Pro Acceso. DSCD n. ${ }^{\circ} 290$, de 20 de marzo de 2013, p. 31.

10 En palabras de Bergareche, corresponsal del diario ABC en Londres. DSCD n. ${ }^{\circ} 295$, de 10 de abril de 2013 , p. 19.

11 Consideración realizada por la Vicepresidenta del Gobierno y Ministra de la Presidencia, Sáenz de Santamaría Antón, en el debate de totalidad del proyecto de ley de transparencia. DSCD n. ${ }^{\circ} 117$, de 30 de mayo de 2013 , p. 4.

12 Diputada Batet Lamaña, por el Grupo Socialista. DSCD n. ${ }^{\circ} 117$, de 30 de mayo de 2013, p. 36.

13 Emilio Olabarría, del Grupo Parlamentario Vasco (EAJ-PNV). DSCD n. ${ }^{\circ}$ 290, de 20 de marzo de 2013, p. 18. 
estableciendo que la implantación de esta normativa permite que los ciudadanos puedan juzgar mejor y con más criterio la capacidad de sus responsables públicos y decidir en consecuencia. Esta circunstancia, el posibilitar una mejor fiscalización de la actividad pública, así como el contribuir con ello a la necesaria regeneración democrática, sin duda promoverá, en opinión del legislador estatal, la eficiencia y eficacia de la Administración y favorecerá el crecimiento económico.

En esta misma línea se expresan otras normas de transparencia autonómicas. Por citar solo algunas, la catalana (Ley 19/2014, de 29 de diciembre, de Transparencia, Acceso a la Información Pública y Buen Gobierno), que reitera que el control de la Administración incide directamente sobre la calidad democrática de la sociedad, en tanto que afecta al conocimiento por parte de la ciudadanía de los datos y de la información de que disponen las administraciones y los poderes públicos, que son determinantes para su toma de decisiones y que los ciudadanos también deben conocer para poder evaluar las actuaciones públicas y garantizar un ejercicio del poder público responsable. También la ley de transparencia andaluza (Ley 1/2014, de 24 de junio, de Transparencia Pública de Andalucía), entiende la transparencia de la actuación de los poderes públicos como uno de los instrumentos que permiten que la democracia sea más real y efectiva. Por su parte, la Ley de Transparencia gallega (Ley 1/2016, de 18 de enero, de Transparencia y Buen Gobierno) subraya que los mecanismos de transparencia y de buen gobierno funcionan como contrapesos que garantizan la protección de la ciudadanía frente a hipotéticas arbitrariedades del poder público y el uso indebido del dinero o patrimonio público, reivindicando la normativa de transparencia como vía para que dicha ciudadanía pase a ser un actor fundamental en el seguimiento, control y vigilancia de la actividad de los poderes públicos. Finalmente, la ley canaria (Ley 12/2014, de 16 de diciembre, de Transparencia y de Acceso a la Información Pública), resalta el hecho de que la pérdida de confianza de la ciudadanía en la gestión pública ha ido en aumento en las últimas décadas, muchas veces nutrida por el desconocimiento de los objetivos y acciones ejecutadas por las instituciones públicas. En este sentido -continúa la norma- la transparencia se revela como uno de los valores esenciales para que las instituciones y administraciones sean consideradas como propias, cercanas y abiertas a las expectativas, necesidades y percepciones de la ciudadanía. A ello se une el notable aumento del interés ciudadano por participar activamente y de forma continuada en el devenir político, social y económico de la sociedad de la que forma parte, para lo cual resulta imprescindible garantizar el acceso a una información pública de calidad, con claridad y agilidad.

En definitiva, son varios los efectos que las diversas normas de transparencia, estatal y autonómicas, pretenden conseguir, muchos de ellos íntimamente conectados: la mejora de la rendición de cuentas a la ciudadanía; la promoción de la participación ciudadana, a partir de una mejor información; el facilitar el ejercicio de derechos de los ciudadanos; la mejora de la relación de la Administración con la ciudadanía; la lucha contra la corrupción; la eficacia y eficiencia de la Administración; una organización de la información pública más racional y efectiva; la satisfacción ciudadana o, de una forma más amplia, el contar con una democracia de mayor calidad.

\section{METODOLOGÍA}

La elección de una determinada metodología como herramienta a través de la cual investigar y aprehender la realidad social constituye un elemento clave en el diseño de toda investigación, partiendo de la necesidad de supeditar siempre el método empleado al objeto de la investigación concreto (Vallejos et al., 2007). En este caso, los objetivos específicos de este trabajo de investigación, aconsejaban la aplicación de diferentes métodos o técnicas de aproximación a dicha realidad, que se han complementado: además del análisis de numerosas fuentes documentales, se ha realizado una encuesta y una serie de entrevistas que han dado voz a los verdaderos protagonistas de la implantación de la transparencia en los municipios: los responsables políticos y los empleados públicos encargados de ejecutar las leyes de transparencia.

Las técnicas de investigación utilizadas en el estudio, realizado en el primer semestre de 2019, han sido las que figuran descritas a continuación.

\subsection{Análisis y estudio de fuentes documentales}

Se ha llevado a cabo el examen de los textos legales vigentes en la materia en el ámbito local, las leyes de transparencia estatal y autonómicas, así como las ordenanzas municipales. Junto a estas, se han manejado toda una serie de importantes fuentes fundamentales en el proceso de aprobación de la Ley 19/13, 
GAPP. Nueva Época - N. 27, noviembre 2021 - ISSN: 1989-8991 - DOI: https://doi.org/10.24965/gapp.i27.10872 - [Págs. 30-48]

LTAIPBG, esenciales para comprender el origen y razón de ser de su articulado: Diarios de sesiones del Congreso y del Senado; Informe del Consejo de Estado; memorias e informes que conforman el expediente de elaboración de este texto normativo.

\subsection{Encuesta a una amplia muestra de los ayuntamientos españoles}

Se trata de una encuesta de ámbito nacional, realizada a Ayuntamientos españoles encuadrados en las 17 Comunidades Autónomas, así como a las dos ciudades autónomas de Ceuta y Melilla. En el uso de dicha técnica de investigación, referida a elementos clave en materia de transparencia en el ámbito local, nos beneficiamos de que las personas entrevistadas tienen como marco de referencia la normativa que están poniendo en práctica, y por tanto las preguntas del cuestionario resultan relevantes para los mismos, en la medida que se debe poseer un nivel de conocimiento y de información suficiente sobre el tema. El cuestionario formula preguntas sobre los diversos indicadores surgidos de la regulación que lleva a cabo la Ley 19/13, LTAIPBG, sobre publicidad activa, derecho de acceso a la información, y buen gobierno, e incluye una mayoría de preguntas cerradas, con alguna parte abierta en determinados casos. Las cuestiones cerradas serán ya de respuesta alternativa dicotómica (sí o no), o bien de respuesta de elección múltiple, estas últimas para temas más complejos. También se ha prestado atención a realizar una adecuada organización temática de las preguntas del cuestionario, que incluya cuestiones introductorias, que facilite una transición fácil entre temas y que concluya de forma adecuada. La fase de pretest ayudó a mejorar el cuestionario antes de lanzarlo, y de realizar finalmente las entrevistas.

TABla 1. Municipios por Comunidades Autónomas

\begin{tabular}{lcc}
\hline & Total & $\%$ \\
\hline Andalucía & 38 & 11,2 \\
\hline Extremadura & 23 & 6,8 \\
\hline Galicia & 9 & 2,7 \\
\hline Illes Balears & 6 & 1,8 \\
\hline Islas Canarias & 15 & 4,4 \\
\hline La Rioja & 8 & 2,4 \\
\hline Navarra & 13 & 3,8 \\
\hline País Vasco & 16 & 4,7 \\
\hline Principado de Asturias & 7 & 2,1 \\
\hline Región de Murcia & 8 & 2,4 \\
\hline Aragón & 35 & 10,3 \\
\hline Cantabria & 3 & 0,9 \\
\hline Castilla y León & 18 & 5,3 \\
\hline Castilla-La Mancha & 26 & 7,7 \\
\hline Cataluña & 53 & 16,5 \\
\hline Ceuta, Ciudad Autónoma & 13 & 0,3 \\
\hline Comunidad de Madrid & 3,8 \\
\hline Comunidad Valenciana & 13,0 \\
\hline Total & 100,0 \\
\hline
\end{tabular}

Fuente: Elaboración propia. 
En cuanto al tipo de entrevista, se utilizó un cuestionario remitido y devuelto on line, con asistencia telefónica y por correo electrónico cuando existían dudas sobre alguna cuestión determinada. Los datos extraídos de las respuestas al cuestionario se codificaron y trabajaron utilizando un soporte informático, el paquete estadístico SPSS (Statistical Package for the Social Sciences), en su versión 24.

Son elementos que definen y refuerzan el importante valor y la calidad de la información obtenida a través de la encuesta utilizada como técnica de investigación:

- El gran número de cuestionarios recibidos, constitutivos de la muestra (339).

- El hecho de que las encuestas correspondan a municipios encuadrados en todas las provincias españolas (51) y comunidades autónomas (17).

- También es muy elevada la representación de los municipios de gran población, dado que poseemos información de más de la mitad de los mismos, así como de otros muchos de singular importancia en la geografía española. En la misma línea, contamos con encuestas correspondientes a un gran número de capitales de provincia.

- Por último, se han procesado y analizado encuestas de municipios encuadrados en todos los rangos de población, con una importante correspondencia con los tamaños de municipios que configuran la realidad local.

Todos los elementos anteriores se constatan en las tablas 1 y 2 .

TABLA 2. MUNICIPIOS POR NÚMERO DE hABITANTES

\begin{tabular}{lcc}
\hline & Total & $\%$ \\
\hline Hasta 1.000 habitantes & 93 & 27,4 \\
\hline De 1.001 a 5.000 habitantes & 100 & 29,5 \\
\hline De 5.001 a 10.000 habitantes & 31 & 9,1 \\
\hline De 10.001 a 20.000 habitantes & 23 & 6,8 \\
\hline De 20.001 a 50.00 habitantes & 38 & 11,2 \\
\hline De 50.001 a 100.00 habitantes & 24 & 7,1 \\
\hline De 100.001 a 500.000 habitantes & 27 & 8,0 \\
\hline Más de 500.000 habitantes & 3 & 0,9 \\
\hline Total & 339 & 100,0 \\
\hline
\end{tabular}

Fuente: Elaboración propia.

El número y tipología de respuestas recibidas a esta encuesta la convierten en una herramienta capaz de proporcionar datos e información numerosos y extraordinariamente ricos a la hora de analizar el proceso de implantación de la transparencia en los ayuntamientos. En particular, en estas páginas se documentan los resultados parciales de un bloque de cuestiones referidas a la valoración de los diversos efectos de la implantación de las leyes de transparencia.

\subsection{Realización de entrevistas en profundidad especializadas}

La investigación se completó con entrevistas semi-estructuradas en profundidad a una selección de personas (20), con perfil político y/o técnico, encargadas de poner en marcha la implantación de las normas de transparencia en la Administración local.

La utilización de este tipo de entrevista, que a grandes rasgos ha versado sobre los mismos ejes temáticos que el cuestionario on line, persigue el profundizar mediante dicha técnica de investigación en la experiencia concreta de los responsables políticos y técnicos que están implementando los requerimientos concretos que conlleva la ley de transparencia en sus respectivas administraciones, y hacerlo a través de 
sus testimonios, privilegiados en una materia que conocen y en un conjunto de cambios en el modo de funcionar tradicional de la Administración que están efectuando directamente.

Se trata de entrevistas especializadas y a élites, tal y como las describe Vallés (2014), siguiendo en gran parte a Dexter (1970), quienes la recomiendan siempre que los objetivos del estudio lo requieran, y estemos ante un entrevistado experto o bien informado. En este caso se ha entrevistado a personas profundamente conocedoras de los cambios que entraña en los ayuntamientos la implantación de la transparencia, al ser protagonistas de dicho proceso, y comprometidas en el objetivo de adaptar los entes locales a los requerimientos de una nueva administración, que el ciudadano pueda conocer y en la que pueda tener mayores niveles de participación.

Todas las estrategias utilizadas en esta investigación se han aplicado de forma complementaria. En particular, se ha buscado profundizar mediante las entrevistas realizadas, en los diversos temas cuyas tendencias e importancia apuntaran los resultados de la encuesta, técnica esta última que no permite a las personas que respondan al cuestionario explayarse. Una y otra herramienta de investigación son útiles en cualquier caso para llevar a cabo una función importantísima, una respecto a la otra: validar o refutar los resultados alcanzados a través de cada una de ellas.

\section{RESULTADOS Y DISCUSIÓN}

\subsection{La eficacia de las leyes de transparencia en los municipios}

Los responsables de los municipios españoles han valorado las consecuencias de la implantación de la transparencia en sus ayuntamientos, y son varios e interesantes los resultados más destacables de dicha evaluación, en la que se han puntuado tales efectos de 0 a 10.

\section{GRÁFIC01. MUNICIPIOS (\%) QUE VALORAN CON UN 0 O CON UN 10 LOS DIVERSOS EFECTOS DE LA IMPLANTACIÓN DE LA TRANSPARENCIA}

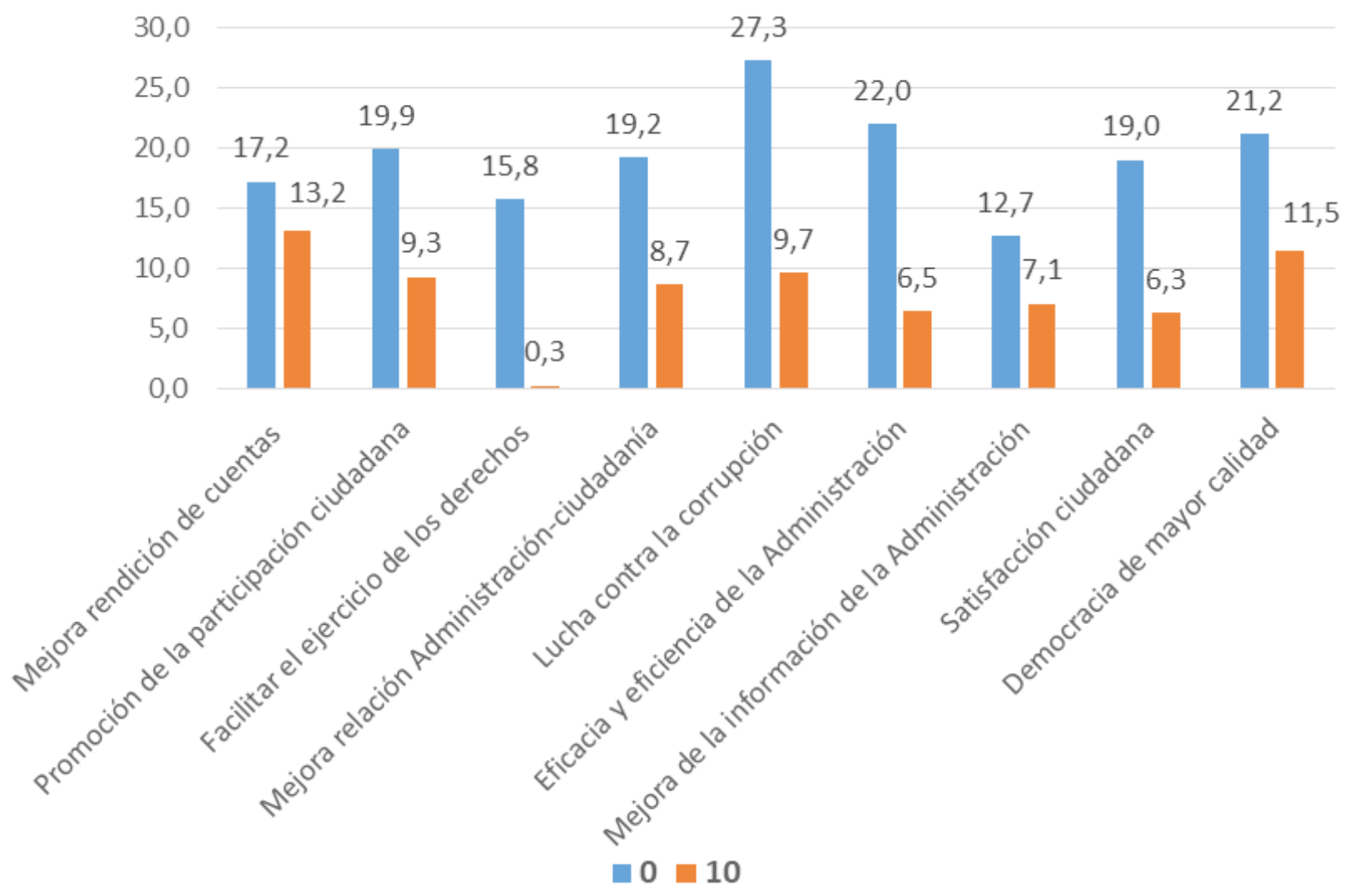

Fuente: Elaboración propia. 
La primera cuestión relevante derivada del estudio realizado, es la constatación de que existe una cifra considerable de municipios, variable en función de los diversos efectos analizados, que son totalmente escépticos en relación a la eficacia de la implantación de las leyes de transparencia, al haber valorado con un 0 las consecuencias de las mismas; dichos ayuntamientos representan una horquilla que oscila del 12,7 al $27,3 \%$, según el diverso efecto analizado. Tales porcentajes son mucho más elevados que los correspondientes a los municipios que se sitúan en el extremo totalmente opuesto, esto es, los totalmente convencidos o entusiastas de la transparencia, que por ello valoran las consecuencias de la misma con un 10, los cuales representan de un 0,3 a un $13,2 \%$ del total.

Así, un número realmente importante de municipios (el 27,3\%) valoran con un 0 las consecuencias de la ley de transparencia en la lucha contra la corrupción, que fue una de las cuestiones sobre las que más se habló como efecto buscado por la normativa en el debate parlamentario que precedió a la aprobación de la ley estatal en la materia, Ley 19/13, LTAIPBG. También existe una proporción alta de ayuntamientos (22\%) que desconfían totalmente de los efectos de las normas de transparencia como instrumento propiciador de mayores niveles de eficacia y eficiencia de la Administración, porcentaje ligeramente superior a los que se muestran absolutamente escépticos con los efectos que cabe reconocer a la transparencia a la hora de mejorar la calidad de la democracia ${ }^{14}(21,2 \%)$ : todos ellos otorgan un 0 a la valoración de los mismos. A continuación, y con valores muy cercanos -en los tres casos entre el 19 y el $20 \%$-, se sitúan los porcentajes de municipios que evalúan con un 0 las consecuencias de la transparencia sobre cuestiones como la promoción de la participación $(19,9 \%$ ), la mejora de la relación entre la Administración y los vecinos del municipio $(19,2 \%)$, o la satisfacción ciudadana $(19 \%)$. En el gráfico 1 se puede observar el número relativo de municipios que ponen en tela de juicio otros tantos efectos que las leyes de transparencia pudieran conseguir en ámbitos diversos.

En el extremo opuesto encontramos los ayuntamientos que valoran en el grado máximo, otorgando un 10 , las diferentes consecuencias potenciales de la ley de transparencia sobre terrenos diversos. Destacan en número el $13,2 \%$ que subraya sus consecuencias en materia de mejora rendición de cuentas; el $11,5 \%$ que lo hace con los efectos de la transparencia a la hora de conseguir una democracia de mayor calidad; o el 9,7\% que concede asimismo la máxima puntuación al evaluar la eficacia de aquella en la lucha contra la corrupción.

Como vemos, existen dos consecuencias de la ley de transparencia que suscitan las opiniones más encontradas por parte de los responsables municipales, dado que cuentan con las mayores proporciones de ayuntamientos que las valoran con las puntuaciones más y menos elevada (10 y 0): se trata de la lucha contra la corrupción y la consecución de una democracia de mayor calidad. Sin embargo, son muchísimos más los municipios que desconfían de tales efectos, y en el caso de la lucha contra la corrupción la diferencia entre los dos grupos de ayuntamientos que conceden las valoraciones más alejadas es de 17,6 puntos.

\subsection{Valoración de los diversos efectos de la transparencia}

Si abandonamos los extremos para apreciar el cuadro global, podemos concluir que los efectos de la ley de transparencia más apreciados -un hecho que se refleja en que más de la mitad de los municipios los han evaluado otorgándoles una puntuación de 6 a 10-, son los siguientes (y en cada caso se indica la proporción de ayuntamientos que les otorga tal valoración):

- Mejora de la organización de información administrativa (60,6\%).

- Facilitar el ejercicio de los derechos de los ciudadanos $(58,2 \%)$.

- Mejora de la rendición de cuentas a la ciudadanía $(55,2 \%)$.

- Consecución de una democracia de mayor calidad (54,5\%).

14 La calidad de la democracia ha sido un factor sobre el cual también se han medido los efectos de las normativas de transparencia, en la medida en que diversos estudios sobre la primera (por todos, Villoria Mendieta, 2018) aluden a dicho elemento, que las normativas de transparencia también mencionan en sus Exposiciones de Motivos, y de que, en los testimonios de los responsables locales encuestados y entrevistados, se advierte que han respondido sin ninguna duda a la pregunta. Soy consciente, no obstante, que se trata de un concepto comprensivo de muchos otros que han sido medidos individualmente, especialmente si manejamos el concepto que de la misma ofrecen autores como Diamond y Morlino (2005), Morlino (2009) -no exento de críticas-, y por ello que quizá sea demasiado amplio, aunque en mi opinión añade a este análisis la valoración de una perspectiva de conjunto, que resulta enriquecedora. 
GAPP. Nueva Época - N. 27, noviembre 2021 - ISSN: 1989-8991 - DOI: https://doi.org/10.24965/gapp.i27.10872 - [Págs. 30-48]

La eficacia de la normativa sobre transparencia: percepciones de los responsables municipales en España

- Mejora de la relación de la Administración pública con la ciudadanía $(54,2 \%)$.

Gráfico 2. VALORAción de Los EFECTOS DE LA IMPLANTACIÓn dE LA TRANSPARENCIA (\% MUNICIPIOS)

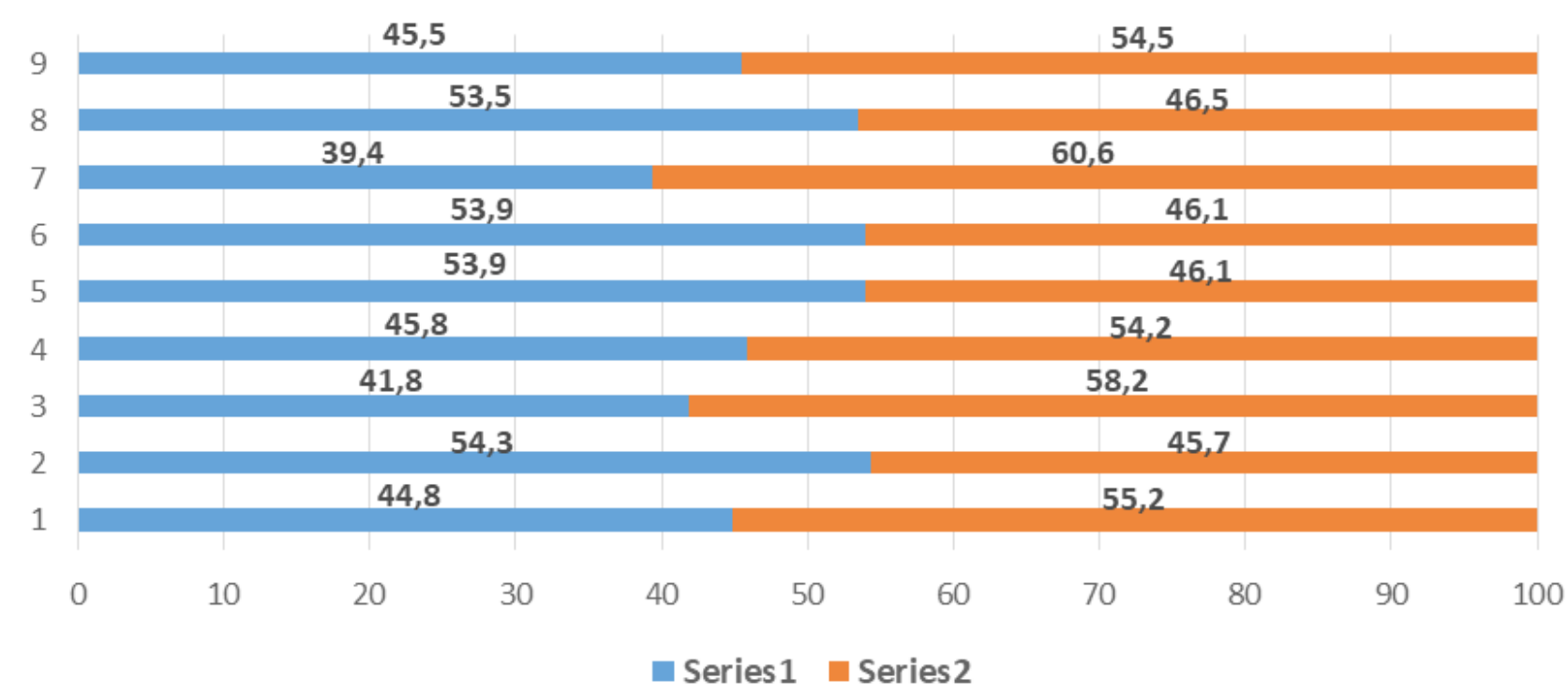

Fuente: Elaboración propia.

Por el contrario, las consecuencias de la normativa de transparencia menos estimadas, una conclusión avalada por el hecho de que más de la mitad de los municipios las valoran escasamente, de 0 a 5 , son las siguientes (de nuevo se indica la proporción de ayuntamientos que otorga tal valoración):

- Promoción de la participación ciudadana (54,3\%).

- Lucha contra la corrupción $(53,9 \%)$.

- Eficacia y eficiencia de la Administración (53,9\%).

- Satisfacción ciudadana (53,5\%).

Resulta sorprendente que dos de los efectos más buscados por las leyes de transparencia (la lucha contra la corrupción y la promoción de la participación ciudadana), tal y como se mencionó repetidamente en el debate parlamentario de la ley estatal, así como se reconoce expresamente en los preámbulos de muchas leyes autonómicas en la materia, sean precisamente dos de los menos reconocidos como consecuencias efectivas de la implantación de la transparencia en el ámbito municipal.

Los argumentos y cifras expresados se aprecian con nitidez en los diversos gráficos de este apartado.

También en las entrevistas se han obtenido testimonios de responsables de ayuntamientos que expresan poca confianza en algunos de los efectos que debiera alcanzar la implantación de las leyes de transparencia; por ejemplo, en las mayores eficacia y eficiencia de la Administración municipal:

«Mira, la administración se ha puesto un poco las pilas, para procurar la información que la ley señala, que es mucha. Pero estamos a años luz de poner en marcha una administración electrónica, en absoluto contamos con sistemas de organización de la información que nos permitan tener datos de calidad disponibles casi de forma automática, o de rutinizar la disponibilidad de determinados indicadores, que son fundamentales en la gestión. Y menos aún en la Administración local, que cuenta con menores recursos. Estamos en el camino, quizá, pero nos queda un buen trecho para funcionar con parámetros de eficiencia a nivel de información» (Entrevista n. ${ }^{\circ}$ 2).

"Yo no creo que se pueda constatar que los ayuntamientos, hasta la fecha, funcionen mejor, que sean más eficientes. Es cierto que el hecho de que tú tengas que mostrar de forma abierta o transparente lo que haces, colgar la documentación, hacerlo en tiempo y forma, o la circunstancia de que cualquier ciudadano te pueda solicitar datos sobre la gestión municipal, y desde el ayuntamiento dicha información deba de estar accesible, o al menos disponible, pues induda- 
blemente va a provocar que te pongas las pilas. Pero yo, hasta el momento, no he constatado una relación clara entre transparencia y eficiencia» (Entrevista n. ${ }^{\circ} 8$ ).

Tampoco otros efectos buscados por el legislador a la hora de aprobar las diversas leyes de transparencia, como el logro de mayores niveles de participación ciudadana, fruto de una información sobre la gestión municipal de calidad, parecen darse demasiado en los ayuntamientos españoles. El interés de la ciudadanía por la información y la actividad municipal es muy discreto, y apenas tiene lugar en los municipios pequeños, lo que se explica por factores como el envejecimiento de su población, la menor actividad socio-económica, el perfil de los vecinos, su cercanía al gobierno y empleados municipales, la brecha digital, o la ausencia de cultura participativa ciudadana. Así se ha subrayado en los testimonios que ofrecen las entrevistas realizadas:

«Pocas, tenemos muy pocas consultas. En estos municipios pequeños, los ciudadanos preguntan directamente a la alcaldesa o a los concejales, y apenas consultan por la web. El contacto y la relación son muy cercanos» (Entrevista $\left.n .^{\circ} 18\right)$.

«Estoy convencido de que las medidas de transparencia son estupendas, pero en un municipio de estas características, con pocos habitantes, donde además la población no tiene acceso a internet y con una media de edad superior a los 70 años, esto tiene poca repercusión» (Entrevista n. ${ }^{\circ} 3$ ).

«Consultas, apenas hay. Quizá la cuestión vaya en relación directa con el tamaño del municipio. También, por supuesto, con el perfil de sus habitantes. En los municipios pequeños, que fijate que son la mayoría, donde los vecinos se dedican a profesiones que apenas tienen, por así decirlo, cariz intelectual, resulta extraño que el ciudadano de a pie te pida datos sobre la gestión municipal. Se interesan únicamente por lo suyo, por lo que les afecta personalmente, y eso te lo preguntan directamente, te lo preguntan por la calle, o como mucho vienen al ayuntamiento y lo consultan» (Entrevista n. ${ }^{\circ}$ 9).

En definitiva, la valoración de las diversas consecuencias de las leyes de transparencia no es demasiado elevada, esto es, desde el ámbito municipal no se considera que la entrada en vigor de las diversas normas en la materia haya propiciado grandes cambios tendentes a la mejora de la Administración, ni a incentivar de un modo destacable la participación ciudadana, ni que los ayuntamientos hayan avanzado de forma apreciable en la rendición de cuentas, ni que nos encontremos ante una sociedad en la que la lucha contra la corrupción y con ella la calidad de la democracia hayan experimentado alteraciones cualitativamente relevantes. Quizá esta relativamente escasa valoración de la eficacia de la implantación de la transparencia sea atribuible, entre otros factores, además de a su reciente aparición en el paisaje de la Administración, a que los ayuntamientos españoles no cumplen la norma en su totalidad. Aunque sin duda influye también el otro extremo subjetivo de la transparencia, esto es, la ciudadanía, cuyo interés en los datos que se hacen públicos tampoco parece ser muy destacable, ni su participación en los asuntos públicos se ha visto modificada por el hecho de contar con una mejor información, tal y como se ha constatado en otro de los apartados del presente estudio. Esta cuestión respondería a factores de variada índole, entre los cuales sin duda habría que considerar la ausencia de una cultura de participación ciudadana.

Las anteriores tendencias se acentúan si tenemos en cuenta el tamaño y la población de los municipios, pudiendo concluirse que los municipios pequeños aprecian escasamente las consecuencias de la ley de transparencia en los diversos ámbitos, mientras que a medida que el tamaño de los mismos aumenta, sus responsables se muestran más sensibles a los efectos positivos de la norma. Ello puede apreciarse con nitidez a través de los siguientes datos, relativos a cada uno de los diversos efectos analizados de la normativa de transparencia:

- En materia de rendición de cuentas, la media de municipios que menosprecia absolutamente las consecuencias de la implantación de la transparencia sobre la misma, valorándolas con un 0 , es del $17,2 \%$, porcentaje que se eleva hasta el $29,5 \%$ en aquellos que no alcanzan los 1.000 habitantes, y es del $20,8 \%$ en los que tienen entre 1.001 y 5.000 .

En la misma línea, si el valor medio de los ayuntamientos que evalúan en mayor grado, de 6 a 10 , tales efectos, es del $55,2 \%$, en aquellos que cuentan con menos de 1.000 vecinos, dicho valor cae 30 puntos, situándose en el $35,2 \%$.

- Por lo que respecta a las consecuencias de la transparencia sobre la participación ciudadana, se repite el patrón anterior. Si son un 19,9\% de municipios los que como media creen que la implantación 
de la transparencia no ha tenido ningún efecto sobre aquella, valorándolo con un 0 , son muchos más los ayuntamientos que comparten dicha opinión a medida que su tamaño y población desciende (en concreto son el $37,5 \%$ de los de menos de 1.000 habitantes, y el $24 \%$ de los que tienen entre 1.001 y 5.000 ). Por el contrario, no hay ningún ayuntamiento de entre 100.001 y 500.000 vecinos, ni de más de medio millón de habitantes, que haya declarado que la transparencia produce nulos efectos en materia de participación, evaluándola con un 0.

$Y$ de nuevo en esta cuestión, solo el $28,4 \%$ de los municipios de menos de 1.000 vecinos valoran el incremento de participación ciudadana consecuencia de la transparencia con la mayor puntuación, entre 6 y 10, mientras que son el $60 \%$ en los ayuntamientos de entre 20.001 y 50.000 habitantes; el $65,2 \%$ de los de entre 50.001 y 100.000 ; el $65,4 \%$ de los de entre 100.001 y 500.000 ; y el $66,7 \%$ en los que superan dicha cifra.

Los testimonios presentes en las entrevistas, de nuevo, van en la misma línea que los datos disponibles:

«Bueno, el grado de participación ciudadana tampoco ha variado de forma ostensible. Yo creo que existen dos sectores de población, los que participan en la gestión municipal, a través de acciones diversas, y los que no lo hacen nunca. Los primeros, lógicamente, pues con la implantación de la normativa de transparencia han ganado mucho, porque ahora disponen de más áreas, datos e iniciativas en las que poder participar, al tener más y mejor información. Pero el segundo grupo, no por ello participa más. Resumiendo, que un aumento de la participación, yo no creo que se haya producido, pero sí existen, indudablemente, más vías para participar, para intervenir de algún modo en la gestión municipal, para aquellos interesados, que siguen siendo básicamente los mismos» (Entrevista n. $\left.{ }^{\circ} 11\right)$.

- En relación con un eventual tercer efecto de la implantación de la transparencia, su capacidad para facilitar el ejercicio de derechos de los ciudadanos/as, un 15,8\% de los municipios han declarado que las novedosas normativas en la materia no han supuesto en absoluto una vía para allanar el ejercicio de tales derechos, y por tanto han valorado la eficacia de la ley en este terreno con un 0.

Una proporción de municipios relativamente alta, que sin embargo prácticamente se duplica en aquellos que no alcanzan los 1.000 habitantes (29,5\%). Esta apreciación se modifica a medida que el tamaño y población de los municipios son mayores, de modo que no hay ningún ayuntamiento entre 100.000 y 500.000 vecinos, ni con más de medio millón de habitantes, que haya ponderado con un 0 las consecuencias de la transparencia en este ámbito.

Si ampliamos el enfoque, considerando los municipios que, sin negar absolutamente las posibles consecuencias de la transparencia a la hora de facilitar el disfrute efectivo de los derechos, no les otorgan una gran importancia (valorándolas, en consecuencia, de 0 a 5 sobre 10), estos suponen el $41,8 \%$ de media. En el grupo de municipios de menos de mil habitantes, sin embargo, son un $58 \%$ (casi 17 puntos más) los que piensan de ese modo, desconfiando en gran medida de las consecuencias de la ley de transparencia en este ámbito. En el extremo opuesto, solo el $11,5 \%$ de los ayuntamientos de entre 100.001 y 500.000 habitantes reconoce una trascendencia tan poco relevante a la transparencia en esta área, y no hay ninguno que valore tan bajo tales efectos, en el grupo de aquellos con más de 500.000 vecinos, ya que todos ellos evalúan tales consecuencias de 6 a 10.

- La mejora de la relación de la Administración con la ciudadanía es una de las consecuencias de la implantación de la transparencia más apreciada por los municipios, ya que más de la mitad (el $54,2 \%$ ) la han valorado en una horquilla de 6 a 10. En el grupo de los ayuntamientos de menos de 1.000 habitantes son mucho menos entusiastas, ya que solo el $37,5 \%$ opina de ese modo. Una cifra tan solo ligeramente superior a la proporción que, dentro de ese mismo grupo, evalúa con un 0 tales efectos (el $31,8 \%$ ), valoración nula que no le otorga ninguno de los ayuntamientos de entre 100.000 y 500.000 vecinos, ni los de población superior a dicha cifra.

Las entrevistas, como en el resto de apartados, corroboran y refuerzan los resultados que extraemos de la encuesta:

«Irrelevante. La entrada en vigor de la normativa de transparencia no ha tenido influencia alguna en la relación del ayuntamiento con la ciudadanía. No ha hecho que dicha relación sea mejor, si es eso lo que me preguntas» (Entrevista n. ${ }^{\circ} 12$ ). 
- También hay grandes diferencias entre municipios por tamaño y población en punto a los efectos de la transparencia en materia de lucha contra la corrupción. Si un número ya muy elevado de municipios, casi 3 de cada diez $(27,3 \%)$ desestima totalmente tales efectos, puntuándolos con un 0 , esta cifra se eleva exponencialmente en los ayuntamientos de menos de 1.000 vecinos, donde casi uno de cada dos (el $46 \%$ ) niega que la normativa de transparencia tenga eficacia alguna en el terreno analizado.

Y dos tercios de este último grupo de municipios (el 66,7\%) no valora tales efectos más allá de un 5 sobre 10. Una proporción prácticamente coincidente con la correspondiente a los ayuntamientos de mayor población que puntúan en mayor medida, de 6 a 10, las consecuencias de la transparencia a la hora de combatir la corrupción, que son el 63,6\% de los de 50.001 a 100.000 habitantes; el $61,5 \%$ de los de entre 100.001 a 500.000 ; y el $66,7 \%$ de los de más de 500.000 vecinos.

Gráfico 3. MUNicipios (\%) POR tAMAÑo Y POBLACIÓN, QUE VALORAN DE 6 A 10 DIVERSAS CONSECUENCIAS DE LA TRANSPARENCIA

\section{$100,0 \%$}
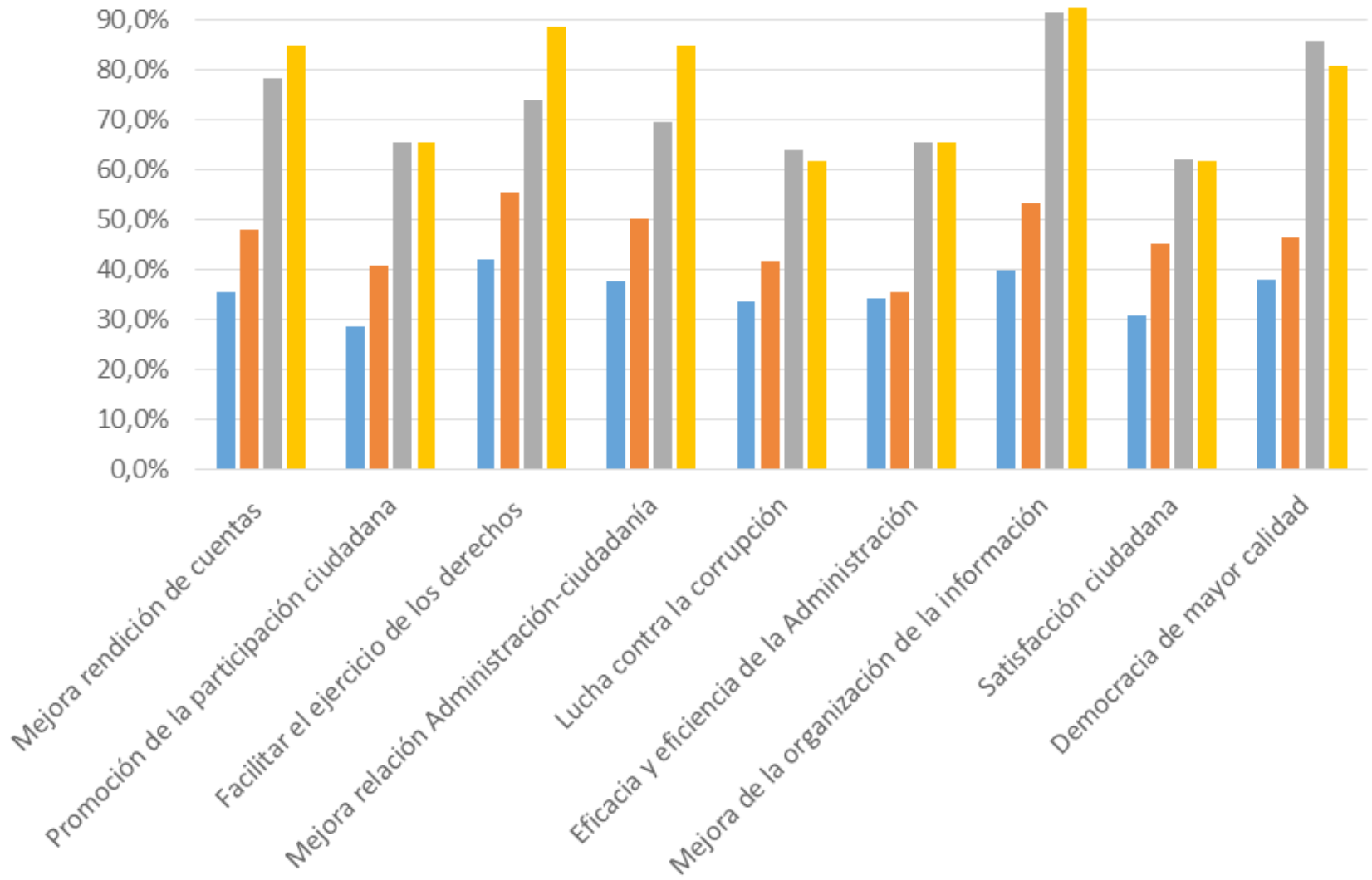

Municipios de hasta 1.000 habitantes

Municipios de 50.001 a 100.000 habitantes

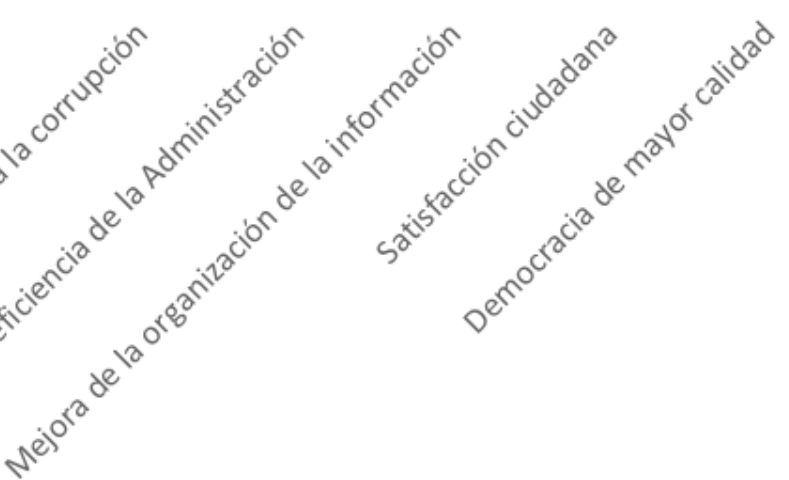

\section{Municipios de 1.001 a 5.000 habitantes Municipios de 100.001 a 500.000 habitantes}

Fuente: Elaboración propia.

- Si consideramos las consecuencias de la transparencia en relación con la eficacia y eficiencia de la Administración, tampoco parece que en general esta sea una consecuencia demasiado apreciada por parte de los municipios, que no han visto que la normativa en la materia genere ayuntamientos más capaces de cumplir sus objetivos con menores costes en recursos de todo tipo. Ello se comprueba a través de varios datos, como ese $22,2 \%$ de municipios que niega cualquier efecto relacionado con un mayor grado de eficacia y eficiencia en la gestión; o el hecho de que una mayoría de los mismos (el $53,9 \%$ ) otorgue una valoración muy limitada a este tipo de consecuencias, puntuándolas de 0 a 5 en una escala que va hasta el 10. 
Para los municipios pequeños, sin embargo, las consecuencias de la transparencia en una gestión de mayor calidad, medida por mayores dosis de eficacia y eficiencia, son prácticamente imperceptibles o muy reducidas, ya que un $35,2 \%$ las consideran nulas, evaluándolas con un 0 , mientras que un $65,9 \%$ de los mismos las valora muy escasamente, entre 0 y 5 .

Se cumple la regla de que, a menor tamaño y habitantes del municipio, más exigua es la apreciación de las bondades de la transparencia en el actuar administrativo, y viceversa, ya que en los ayuntamientos de mayor población sí se estima en mayor medida que las mismas redundan en más excelencia en la gestión administrativa. Así lo demuestra la proporción de municipios que valora esta cuestión entre 6 y 10 , que son el $65,2 \%$ de los que tienen entre 50.001 y 100.000 vecinos; el $65,4 \%$ de los de entre 100.001 y 500.000 , y el $66,7 \%$ de los que superan los 500.000 .

- La mejora de la organización de la información pública ha sido un hándicap básico para la implantación de la ley de transparencia, en la medida en que en la administración española en general, y en la local en particular, no se había hecho un esfuerzo previo de simplificación de procedimientos, ni estaba plenamente implantada la administración electrónica, ni se habían organizado y sistematizado previamente la totalidad de los datos y documentos a ofrecer a la ciudadanía mediante las obligaciones de publicidad activa, ni a través del ejercicio de su derecho de acceso a la información. La efectiva entrada en vigor de la normativa de transparencia y el rodaje de la misma, ha exigido de la Administración local un esfuerzo para mejorar la generación y disposición de su información, y dicha consecuencia ha sido evaluada por los responsables de la transparencia de los diversos municipios.

En la valoración de tales efectos, de nuevo encontramos importantes diferencias entre ayuntamientos, en función de su diverso tamaño y población. Los más pequeños apenas aprecian cambios relevantes en la organización de la información pública, mientras que los más grandes y de mayor población, reconocen que la implantación de la normativa ha traído consigo mejoras en el modo en que producen, ordenan y sistematizan los datos y documentos.

Así, uno de cada cuatro municipios (el $25 \%$ ) con menos de 1.000 vecinos, y el $15,6 \%$ de los que están entre 1.001 y 5.000, niegan cualquier efecto de la transparencia sobre la mejora de su información (puntúan tal cuestión con un 0). Por el contrario, no hay ningún ayuntamiento con una población entre 100.001 y 500.000 , ni superior a dicha cifra, que desprecie totalmente tales consecuencias.

En la misma línea, si solo 4 de cada 10 municipios de menos de 1.000 habitantes (el 39,8\%) conceden una valoración elevada a la eficacia de la implantación de las obligaciones de transparencia sobre la mejora de la información (otorgando una puntuación de 6 a 10), en el grupo de 50.001 a 100.000 son el $91,3 \%$, y en el de los que tienen entre 100.001 y 500.000 habitantes son el $92,3 \%$.

De nuevo, en las entrevistas, como en otras cuestiones existen opiniones contrapuestas:

«La necesidad de tener disponible un gran caudal de información, ya para su publicidad, o para el caso de que cualquier interesado pregunte cualquier dato, nos obliga, de algún modo, a organizar mejor la información, a crear circuitos para saber dónde encontrarla con celeridad. No es que hayamos mejorado una barbaridad, pero desde luego sí lo hemos hecho hasta cierto punto» (Entrevista n. $\left.{ }^{\circ} 18\right)$.

«Yo creo que no hemos mejorado en cuanto a organización de la información se refiere, con la entrada en vigor de la ley de transparencia. Pero no es menos cierto que, desde hace algún tiempo, muchas normativas sectoriales ya imponían la necesidad de tener disponible e incluso de publicar, cierta información, documentos, datos... Por tanto, si hacemos balance, por ejemplo, de la última década, pues ahí sí que hemos avanzado. Pero no de forma específica con la normativa de transparencia» (Entrevista n. ${ }^{\circ}$ ).

- En relación con la satisfacción ciudadana, tampoco parece que los municipios más pequeños entiendan que la puesta en marcha de la transparencia haya supuesto un incremento relevante en el grado de bienestar de los ciudadanos, ya que un tercio (el $33 \%$ ) de aquellos que tienen menos de 1.000 vecinos rechaza de forma absoluta la existencia de tal consecuencia. Prácticamente siete de cada diez municipios de este grupo (el $69,3 \%$ ), así como el $54,8 \%$ de los que están entre 1.001 y 5.000 habitantes, han valorado de forma muy lacónica el bienestar ciudadano consecuencia de la transparencia, otorgándole de 0 a 5 puntos en una escala de 10. 
Más relevancia otorgan a la mejora de la satisfacción ciudadana producto de la transparencia los ayuntamientos más grandes, ya que un $61,9 \%$ de los que están entre 50.001 a 100.000 habitantes, un $61,5 \%$ de los que tienen entre 100.001 y 500.000 , y un $50,0 \%$ de los que superan dicha cifra, han valorado de 6 a 10 tales efectos. Son proporciones ciertamente más amplias que ese $30,7 \%$ de municipios con una población menor a 1.000 vecinos.

- Finalmente, al analizar en qué medida la transparencia de la Administración local ha sido capaz de promover la consecución de una democracia de mayor calidad, también existe una dualidad de opiniones bien diferenciadas, y de nuevo el eje divisorio es el tamaño y población de los municipios. Si los más pequeños refutan tal circunstancia (un $35,6 \%$ directamente la niegan, puntuando con un 0 dicho efecto), en los más grandes y con mayor número de habitantes reconocen en cierto modo que la transparencia ha posibilitado algunos avances democráticos.

Así, no hay ningún municipio de entre 100.001 y 500.000 vecinos, ni con población mayor, que rechace totalmente dichos efectos. Existe, además, una elevada proporción de ayuntamientos grandes que valoran de 6 a 10 las mejoras democráticas consecuencia de la transparencia: son el $68,6 \%$ de los de 20.001 a 50.000 habitantes; el $85,7 \%$ de los de entre 50.001 y 100.000 ; y el $80,8 \%$ de los que tienen entre 100.001 y 500.000 . Sin embargo, tales cifras se desploman hasta el $37,9 \%$ que otorga dicha evaluación positiva, en el grupo de los municipios de menos de 1.000 vecinos.

\section{CONCLUSIONES}

La presente investigación ha tenido como objetivo central la medición de la efectividad de las leyes de transparencia en la Administración local española, a través del prisma de los responsables municipales, estudiando su impacto en toda una serie de aspectos clave, expresamente perseguidos por la normativa, como son la eficacia y eficiencia de la Administración, la lucha contra la corrupción, la promoción de la participación ciudadana, la rendición de cuentas, o la mejora de la organización de la información municipal, entre otras cuestiones. Para ello se han combinado diversas técnicas de investigación (análisis de relevantes fuentes documentales, realización de una encuesta a un importante número de municipios de todas las CC.AA, así como entrevistas en profundidad a responsables de la transparencia municipal), que nos permitieran reforzar y validar los resultados alcanzados.

El tiempo transcurrido desde la implantación de la normativa de transparencia en el ámbito local, no impide evaluar, hasta la fecha, algunas consecuencias y efectos de la misma que pueden ya sentirse.

En este sentido, constatamos, valoraciones relativamente modestas de los efectos de la implantación de la normativa de transparencia en relación a todas las consecuencias analizadas, que son todavía menores en relación a algunos de los efectos más perseguidos por las leyes de transparencia estatal y autonómicas, a tenor de las manifestaciones del legislador y de los debates parlamentarios, como son, entre otros, la lucha contra la corrupción, la satisfacción ciudadana o la promoción de una mayor participación de la sociedad en los temas públicos.

La evaluación de tales efectos es todavía menor en los en los municipios más pequeños y de menos habitantes, mientras que gozan de una mejor apreciación en los ayuntamientos de mayor tamaño y población, donde factores como la mayor capacidad y recursos de toda índole de la Administración para cumplir con la normativa, así como un interés y una demanda ciudadana de información más acentuados, han permitido estimar en mayor medida cambios fruto de la transparencia en los diversos terrenos.

En definitiva, y valorando positivamente los cambios habidos en el panorama de la administración española, particularmente en la local, en materia de transparencia en los últimos años, la reciente implantación de la ley motiva que quede todavía mucho terreno para la mejora en terrenos diversos que pasan por el compromiso político, la dotación de recursos humanos, tecnológicos y económicos, la formación y sensibilización de los empleados públicos, y las transformaciones culturales en la propia administración y en su relación con la ciudadanía. Son necesarios avances que traspasen la superficie y provoquen cambios de fondo en el funcionamiento de la administración municipal en materia de apertura y rendición de cuentas, capacitando con ello a los ciudadanos para la participación en la toma de decisiones, en el marco del desarrollo de políticas de gobierno abierto, hasta alcanzar un grado de cumplimiento razonable de los estándares de calidad que nos permita calificar a los municipios españoles como ayuntamientos transparentes del siglo XXI. Los avances en la implantación de una cultura de transparencia, probablemente permitirán valorar en mayor medida la 
consecución de los efectos buscados por las leyes existentes en la materia, que hoy por hoy no acaban de constatarse en la administración municipal española, salvo en los ayuntamientos de mayor tamaño, donde el grado de cumplimiento de la ley por parte de la administración y el interés de la ciudadanía por la información son mayores.

Ya expuestas las conclusiones alcanzadas, este estudio tiene fortalezas y limitaciones que resulta importante mencionar.

Su limitación fundamental proviene del hecho de que la normativa de transparencia es de reciente implantación en la Administración local. Así, pese a la existencia de alguna ley autonómica en la materia aplicable a los entes locales, con carácter general, los ayuntamientos tuvieron hasta finales de 2015 para adaptarse a las obligaciones de publicidad activa y la garantía del derecho de acceso a la información, contenidas en la Ley 19/13, LTAIPBG. Si a ello añadimos el que las normas de transparencia supusieron una transformación sustancial del modo tradicional de funcionar las administraciones, y no se vieron acompañadas en su implantación por la necesaria dotación de recursos personales, materiales, informáticos, formativos, etc., de todo ello se deriva que los efectos analizados de la implantación de esta normativa en los diversos ámbitos, pueden percibirse como escasos. Los resultados de esta investigación podrían verse alterados si consideramos series temporales más amplias.

Frente a esta limitación, resulta fundamental subrayar una fortaleza importante de este estudio, que es que no existe ningún trabajo que haya abordado en nuestro país en el ámbito local las percepciones sobre la efectividad de las leyes de transparencia, de boca de sus protagonistas, responsables políticos y empleados públicos, que han liderado y ejecutado cambios y transformaciones drásticas en esta materia, con importantes implicaciones. Ello le confiere un valor añadido importante, y enlaza con otros estudios, citados en el marco teórico, que subrayan la importancia de los objetivos buscados por la normativa, en materias como la rendición de cuentas, la eficiencia o la corrupción, por citar solo algunos, y la conexión entre la transparencia y cada uno de estos factores. Por todo ello, este estudio representa un paso inicial importante para abordar el imprescindible análisis de los efectos de la regulación de la transparencia: si todas las normativas deben ser evaluadas, en mayor medida debe serlo ésta, por su carácter novedoso y revolucionario, y el ámbito local es un escenario ideal para hacerlo. Es, por ello, esencial continuar realizando análisis rigurosos sobre este tema, contemplando términos de evaluación más amplios, que además nos posibiliten comparaciones y medición de tendencias, con objeto de crear una línea de estudios consolidados sobre la efectividad práctica de la transparencia, una cuestión esencial para una Administración que funciona con estándares nuevos, para una ciudadanía cuyas demandas son asimismo diversas.

\section{REFERENCIAS BIBLIOGRÁFICAS Y LEGISLATIVAS}

Ackerman, S.-R. (24 de mayo de 2001). La Corrupción y los Gobiernos: Causas, consecuencias y reformas. Siglo XXI de España Editores.

Armstrong, E. (2005). Integrity, transparency and accountability in public administration: recent trends, regional and international developments and emerging issues. United Nations. Department of Economic and Social Affairs.

Bauhr, M.; Grimes, M. (2012). What is government transparency? New measures and relevance for quality of government [Working paper series: 2012:16]. QOG. The Quality of Government Institut, University of Gothenburg. http://hdl.handle.net/2077/38960

Bellver, A.; Kaufmann, D. (2005). Transparenting Transparency: Initial Empirics and Policy Applications [Discussion paper]. The World Bank.

Bentham, J. (1962). The Works of Jeremy Bentham (2. ${ }^{a}$ Edición). Russell \& Russell.

Bovens, M. (2007). Public Accountability. En E. Ferlie, L. E. Lynn Jr. y C. Pollit (eds.), The Oxford Handbook of Public Management (pp. 182-208. https://doi.org/10.1093/oxfordhb/9780199226443.003.0009

Chong, A., de la O, A. , D. Karlan y L. Wantchekon (2011). Looking beyond the incumbent: The effects of exposing corruption on electoral outcomes [NBER working paper series 17679]. National Bureau of Economic Research. https://www.nber.org/papers/w17679

Constant, B. (1988). Political Writings. Cambridge University Press.

Cunill, N. (2006). La transparencia en la gestión pública. ¿Cómo construirle viabilidad? Estado, Gobierno, Gestión pública. Revista chilena de Administración pública, 8, 22-44.

Dahl, R. (1999). La democracia. Una guía para los ciudadanos. Taurus.

Dexter, L. (1970). Elite and Specialized Interviewing. Northwestern University Press.

Diamond, L., Morlino, L. (2005). Introduction, en L. Diamond y L. Morlino (eds.). Assessing the quality of democracy (pp. 1-15). Johns Hopkins University Press. 
GAPP. Nueva Época - N. 27, noviembre 2021 - ISSN: 1989-8991 - DOI: https://doi.org/10.24965/gapp.i27.10872 - [Págs. 30-48]

La eficacia de la normativa sobre transparencia: percepciones de los responsables municipales en España

Raquel Valle Escolano

Morlino, L. (2009). La calidad de democracia. Claves de Razón Práctica, 193, 26-35.

Florini, A. M. (2000). Does: the invisible hand need a transparent glove?: the politics of transparency. Research Collection School of Social Sciences at Institutional Knowledge at Singapore Management University, 2092, 163184. https://ink.library.smu.edu.sg/soss_research/2092

Fox, J. (2007). The Uncertain Relationship between Transparency and Accountability. Development in Practice, 17(4-5). 663-671. https://doi.org/10.1080/09614520701469955

Gray, R. (1992). Accounting and environmentalism: An exploration of the challenge of gently accounting for accountability, transparency and sustainability. Accounting, Organizations and Society, 17(5), 399-425. https://doi. org/10.1016/0361-3682(92)90038-T

Grimmelikhuijsen, S. (2012). Transparency of Public Decision-Making: Towards Trust in Local Government? Policy and Internet, 2(1), 5-35. https://doi.org/10.2202/1944-2866.1024

Grimmelikhuijsen, S. G. y Feeney, M. K. (2017). Developing and testing an integrative framework for open government adoption in local governments. Public Administration Review, 77(4), 579-590. https://doi.org/10.1111/puar.12689

Grimmelikhuijsen, S. G., Piotrowski, S. G. y Van Ryzin, G. G. (2020). Latent transparency and trust in government: Unexpected findings from two survey experiments. Government Information Quarterly, 37(4), artículo 101497. https://doi.org/10.1016/j.giq.2020.101497

Guichot Reina, E. (2014). El sentido, el contexto y la tramitación de la Ley de transparencia, acceso a la información pública y buen gobierno. En E. Guichot Reina (coord.), Transparencia, Acceso a la Información Pública y Buen Gobierno. Estudio de la Ley 19/2013, de 9 de diciembre (pp. 17-34). Tecnos.

Islam, R. (2003). Do More Transparent Governments Govern Better? [Policy Research Working Paper 3077]. World Bank. https://doi.org/10.1596/1813-9450-3077

Jiménez González, J. L. (2013). Corrupción local en España. Cuadernos económicos de ICE, 85, 23-41. https://doi. org/10.32796/cice.2013.85.6050

Ley 8/2018, de 14 de septiembre, de Transparencia, Buen Gobierno y Grupos de Interés (2018). Boletín Oficial del Estado, 253, sec. I, de 19 de octubre de 2018, 101566-101601. https://www.boe.es/eli/es-as///2018/09/14/8

Ley 1/2016, de 18 de enero, de transparencia y buen gobierno (2016). Boletín Oficial del Estado, 81, sec. I, de 4 de abril de 2016, 23489-23522. https://www.boe.es/eli/es-ga/l/2016/01/18/1

Ley 8/2015, de 25 de marzo, de Transparencia de la Actividad Pública y Participación Ciudadana de Aragón (2015). Boletín Oficial del Estado, 115, sec. I, de 14 de mayo de 2015, 41520-41556. https://www.boe.es/eli/es$\operatorname{ar} / / / 2015 / 03 / 25 / 8$

Ley 1/2014, de 24 de junio, de Transparencia Pública de Andalucía (2014). Boletín Oficial del Estado, 172, sec. I, de 16 de julio de 2014, 56133-56163. https://www.boe.es/eli/es-an///2014/06/24/1

Ley 12/2014, de 16 de diciembre, de Transparencia y Participación Ciudadana de la Comunidad Autónoma de la Región de Murcia (2014). Boletín Oficial del Estado, 8, sec. I, de 9 de enero de 2015, 1977-2010. https://www.boe. es/eli/es-mc///2014/12/16/12

Ley 19/2014, de 29 de diciembre, de transparencia, acceso a la información pública y buen gobierno (2014). Boletín Oficial del Estado, 18, sec. I, de 21 de enero de 2015, 4300-4342. https://www.boe.es/eli/es-ct///2014/12/29/19

Ley 19/2013, de 9 de diciembre, de transparencia, acceso a la información pública y buen gobierno (2013). Boletín Oficial del Estado, 295, sec. I, de 10 de diciembre de 2013, 97922-97952. https://www.boe.es/eli/ es/l/2013/12/09/19

Meijer, A. (2014). Transparency. En M. Bovens, R. E. Goodin y T. Schillemans (eds.), The Oxford Handbook of public accountability (pp. 507-524). Oxford University Press.

Michels, A. y Meijer, A. (2008). Safeguarding public accountability in horizontal government. Public Management Review, 10(2), 165-173. https://doi.org/10.1080/14719030801928490

Mulgan, R. (2012). Transparency and Public Sector Performance [Report. Occasional Paper, 1]. The Australia and New Zealand School of Government. https://www.oic.qld.gov.au/_data/assets/pdf_file/0019/7651/93_1-MulganTransparency-and-Public-Sector-Performance_0.pdf

Ponce Solé, J. (2012). La prevención de la corrupción mediante la garantía del derecho a un buen gobierno y a una buena administración en el ámbito local: (con referencias al Proyecto de Ley de transparencia, acceso a la información pública y buen gobierno). En Anuario del Gobierno Local (pp. 93-140). Fundación Democracia y Gobierno Local.

Prats Català, J. (2007). La lucha contra la corrupción como parte integrante del Derecho, el deber y las políticas de buena administración. Cuadernos de derecho público, 31, 11-30. https://revistasonline.inap.es/index.php/CDP/ article/view/811

Schedler, A. (2011). ¿Qué es la rendición de cuentas?. En J. Sosa (ed.). Transparencia y rendición de cuentas (pp. 77106). Siglo XXI Editores.

Solé Ollé, A. y Sorribas Navarro, P. (2014). Does corruption erode trust in government? Evidence from a recent surge of local scandals in Spain [Documento de Trabajo 2014/26]. Instituto de Economía de Barcelona (IEB). http://dx.doi. org/10.2139/ssrn.2471064

Stiglitz, J. (2000). The Contribution of the Economics of Information to the Twentieth Century Economics. The Quarterly Journal of Economics, 115(4), 1441-1478. https://doi.org/10.1162/003355300555015 
Stiglitz, J. (2002). Transparency in Government. The Right to Tell. World Bank.

Vallejos, A. F., Ortí, M. y Agudo, Y. (2007). Métodos y técnicas de investigación social. Ramón Areces.

Valles, M. S. (2014). Entrevistas cualitativas (2. ${ }^{a}$ ed.). Centro de Investigaciones Sociológicas.

Villoría Mendieta, M. (2012). Transparencia y valor de la transparencia. Marco conceptual. En R. Jiménez Asensio, J. Lizcano Álvarez y M. Villoria Mendieta, La transparencia en los gobiernos locales: una apuesta de futuro (pp. 7-28). Fundación Democracia y Gobierno local. http://www.gobiernolocal.org/docs/publicaciones/ Transparencia_ponencias2.pdf

Villoría Mendieta, M. (2018). La transparencia, la imparcialidad y la calidad de la democracia. Dilemata, Revista Internacional de Éticas Aplicadas, 27, 311-331. https://www.dilemata.net/revista/index.php/dilemata/article/ view/412000211

Villoría Mendieta, M. y Cruz-Rubio, C. (2015). Gobierno abierto, transparencia y rendición de cuentas. En M. Villoria Mendieta (dir.) y X. Forcadell Esteller (coord.), Buen gobierno, transparencia e integridad institucional en el gobierno local. Tecnos - Diputació de Barcelona.

Villoria Mendieta, M., Gimeno Feliú, J. M. y Tejedor Bielsa, J. (2016). La corrupción en España. Ámbitos, causas y remedios jurídicos. Atelier. 